\title{
Long-term thermal conditions on the nesting beaches of green turtles on Ascension Island
}

\author{
Graeme C. Hays*, Brendan J. Godley, Annette C. Broderick \\ School of Biological Sciences, University of Wales Swansea, Singleton Park, Swansea SA2 8PP, United Kingdom
}

\begin{abstract}
On 2 of the major nesting beaches used by green turtles Chelonia mydas on Ascension Island, we measured the sand temperature at nest depths throughout the year For both beaches, the sand temperature was strongly correlated $\left(r^{2} \geq 0.94\right)$ with air temperature. We therefore used past records of air temperature to reconstruct sand temperatures on the different beaches throughout the nesting season between 1985 and 1998. This analysis showed that inter-annual differences in sand temperature were small and, while there were consistent thermal changes during the nesting season, over the $14 \mathrm{yr}$ there was little overlap in the temperatures on the 2 beaches, with one being $2.6^{\circ} \mathrm{C}$ warmer, on average, than the other. This work suggests that inter-beach thermal variation is the major mechanism by which a range of incubation temperatures are realised on Ascension Island and hence is likely to facilitate the production of hatchlings of both sexes.
\end{abstract}

KEY WORDS: Sea turtle - Chelonia mydas - Incubation temperature - Temperature-dependent sex determination. Ascension Island

For marine turtles the sex of offspring is determined by their incubation temperature with females being produced when the nest is warmer (generally above $29^{\circ} \mathrm{C}$ ) and males when it is cooler (generally below $29^{\circ} \mathrm{C}$ ) (Ackerman 1996). Consequently, the factors that influence incubation temperature play a central role in the dynamics of sea turtle populations. There are a number of factors that may lead to the range of temperatures needed to produce hatchlings of both sexes. For example, incubation temperature may vary with the date during the season, latitudinally over the nesting range of a population, locally with the specific site on a beach (e.g. whether a nest is shaded or unshaded), with episodic events such as heavy rain and with the depth of the eggs (Morreale et al. 1982, Mrosovsky et al. 1984, Mrosovsky 1988).

'E-mail: g.hays@swan.ac.uk
Interestingly, for green turtles Chelonia mydas nesting on Ascension Island $\left(7^{\circ} 57^{\prime} \mathrm{S}, 14^{\circ} 22^{\prime} \mathrm{W}\right)$ most of these avenues will provide only a limited range of incubation temperatures. The remoteness of Ascension Island and the size of the nesting green turtle population make this a unique rookery. The island is small (approximately $7 \mathrm{~km}$ in diameter) with no other known nesting areas for this population and so significant latitudinal variations in nest temperatures do not exist; local variations in incubation temperature within individual beaches are small (Hays et al. 1995); the nests are so deep that depth-related variations in incubation temperature are minimal (Carr \& Hirth 1962) and rain seldom percolates to the nest so that rain showers have little impact on incubation temperatures (Mortimer 1990). The mechanisms by which a range of incubation temperatures are produced on Ascension Island are therefore puzzling although there are a number of possibilities. For example, large inter-beach thermal variations may exist (Hays et al. 1995); there may be ecologically significant seasonal changes in sand temperature and there may potentially be large interannual thermal differences. The question of interannual differences is particularly pertinent to sea turtles since females are long lived and may nest in several years, and yet long-term records of beach temperatures are conspicuous by their absence (Ackerman 1996). Hence the ability to develop methods of reconstructing past sand temperatures is vital to assess the overall hatchling sex ratio produced over ecologically relevant time-scales (decades). The aim of our study was to try and shed some light on how hatchlings of both sexes are produced on Ascension and to achieve this aim we set out to assess the relative importance of inter-beach, seasonal and inter-annual thermal variations.

Methods. In 1992, sand temperature measurements were made with Grants Instruments temperature probes (model CM-U-V5-1, Grants Instruments Ltd, Barring- 
ton, Cambridge) (Hays et al. 1995). These probes were factory calibrated to give a maximum deviation from the true temperature of $0.2^{\circ} \mathrm{C}$. In $1997 / 1998$ sand temperature measurements were made with Tinytalk II data loggers (Gemini Data Loggers, Chichester, UK). To establish the absolute accuracy of these loggers, in the laboratory they were cross-calibrated against mercury thermometers of known absolute accuracy (NAMAS certified to read within $0.1^{\circ} \mathrm{C}$ of the absolute temperature) over temperatures ranging from 18 to $34^{\circ} \mathrm{C}$. The loggers always gave readings that were within $0.3^{\circ} \mathrm{C}$ of the NAMAS temperature and the mean deviation in corresponding readings among the loggers was $<0.05^{\circ} \mathrm{C}$.

We measured sand temperatures on 2 nesting beaches: Long Beach, where the sand is relatively light in colour and has a high albedo; and NE Bay Beach, where the sand is darker and has a low albedo (Hays et al. 1995). These are 2 of the key nesting beaches on Ascension, accounting for about 16 and $14 \%$ of the total nests laid on the island respectively (Mortimer \& Carr 1987).

All measurements were made by burying probes or loggers at a depth of $75 \mathrm{~cm}$ (which is within the range of nest depths) in the zone of maximal nesting density. In 1992 measurements were made once a day throughout March and April at 1 site on Long Beach. In May 1997, 2 loggers were buried approximately $400 \mathrm{~m}$ apart on Long Beach and 1 on NE Bay Beach and then temperature was logged every $4 \mathrm{~h}$ from the start of May 1997 until the end of February 1998

The UK Meteorological Office provided air temperature measurements made at the airport on Ascension Island. Each day the Meteorological Office routinely recorded the minimum and maximum air temperature and then synopses of these data were calculated each month: namely the monthly mean of all the daily maximum temperatures and the monthly mean of all the daily minimum temperatures. These synoptic data were available for every month from January 1985 until February 1998.

Results and discussion. None of the loggers revealed any diel variation in sand temperature. This is consistent with our previous observations (Hays et al. 1995) and is presumably due to the great depth at which loggers were placed. There was very little thermal variation between the 2 loggers buried for 10 mo on Long Beach. For example, these 2 loggers gave mean daily readings that were, on average, within $0.3^{\circ} \mathrm{C}$ of each other over the 10 mo of logging. This is again consistent with a more extensive set of previous observations which showed that the extent of intra-beach thermal variations on Ascension Island is small (Hays et al. 1995).
Sand temperature varied systematically through the year in line with the variations in air temperature. The relationship between the mean monthly air temperature and the mean monthly sand temperature was very strong for both beaches (Fig. 1a), allowing historic sand temperatures to be reconstructed from the longterm meteorological measurements (Fig, 1b). The reconstructed sand temperatures for the nesting season (January to June) show that inter-annual thermal variations were small and, while there were consistent seasonal changes, overall there was little overlap between the temperatures on the 2 beaches, with NE Bay Beach being relatively warm (mean monthly tempera-
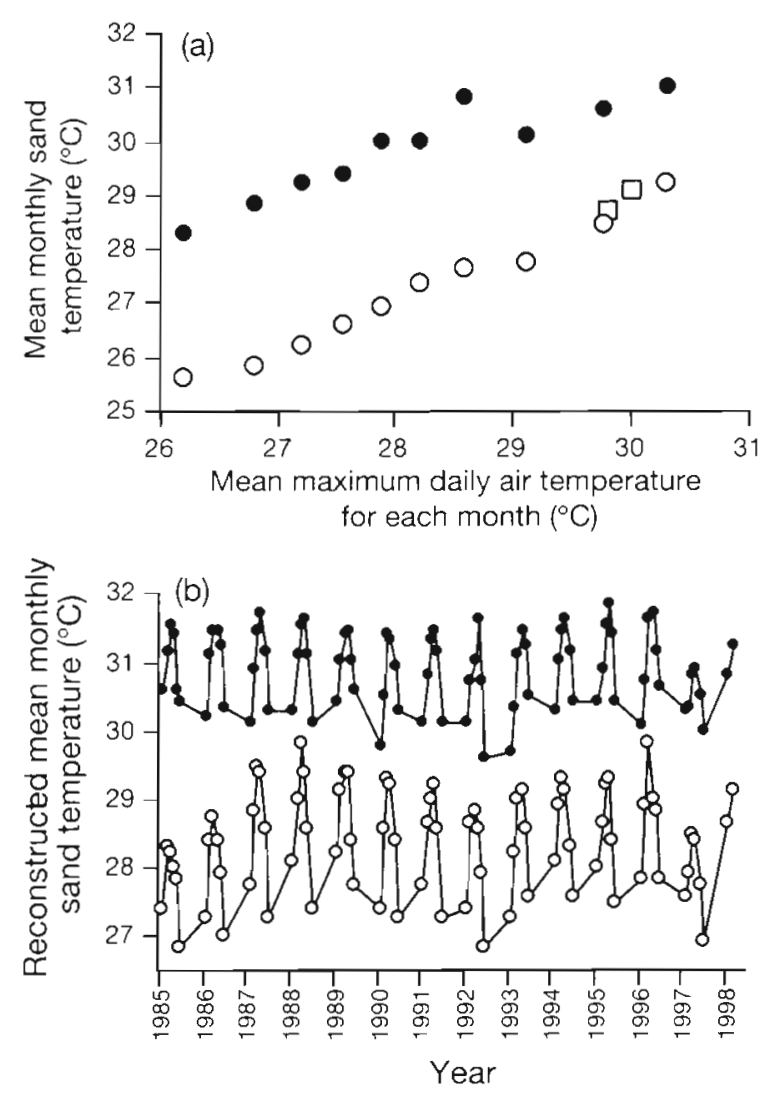

Fig. 1. (a) Relationships between the mean daily maximum air temperature recorded each month and the mean monthly sand temperature measured on Long Beach $(O, \square)$ and NE Bay Beach (1). Circles show measurements made from 1 May 1997 until 28 February 1998; squares show measurements made throughout March and April 1992. The equations which explained most of the variation in the mean monthly sand temperature from routinely measured meteorological variables were: sand temperature on NE Bay Beach $\left({ }^{\circ} \mathrm{C}\right)=12.7+$ 0.745 mean daily minimum air temperature for each month $\left(F_{1,8}=121, \mathrm{p}<0.001, \mathrm{r}^{2}=0.94\right)_{i}$ sand temperature on Long Beach $\left({ }^{\circ} \mathrm{C}\right)=1.6+0.908$ mean daily maximum air temperature for each month $\left(F_{1,10}=498, \mathrm{p}<0.001, \mathrm{r}^{2}=0.98\right)$. (b) The reconstructed mean monthly sand temperatures on Long Beach (o) and NE Bay Beach (-) during the nesting season (JanuaryJune) between 1985 and 1998, using the equations given in (a) 

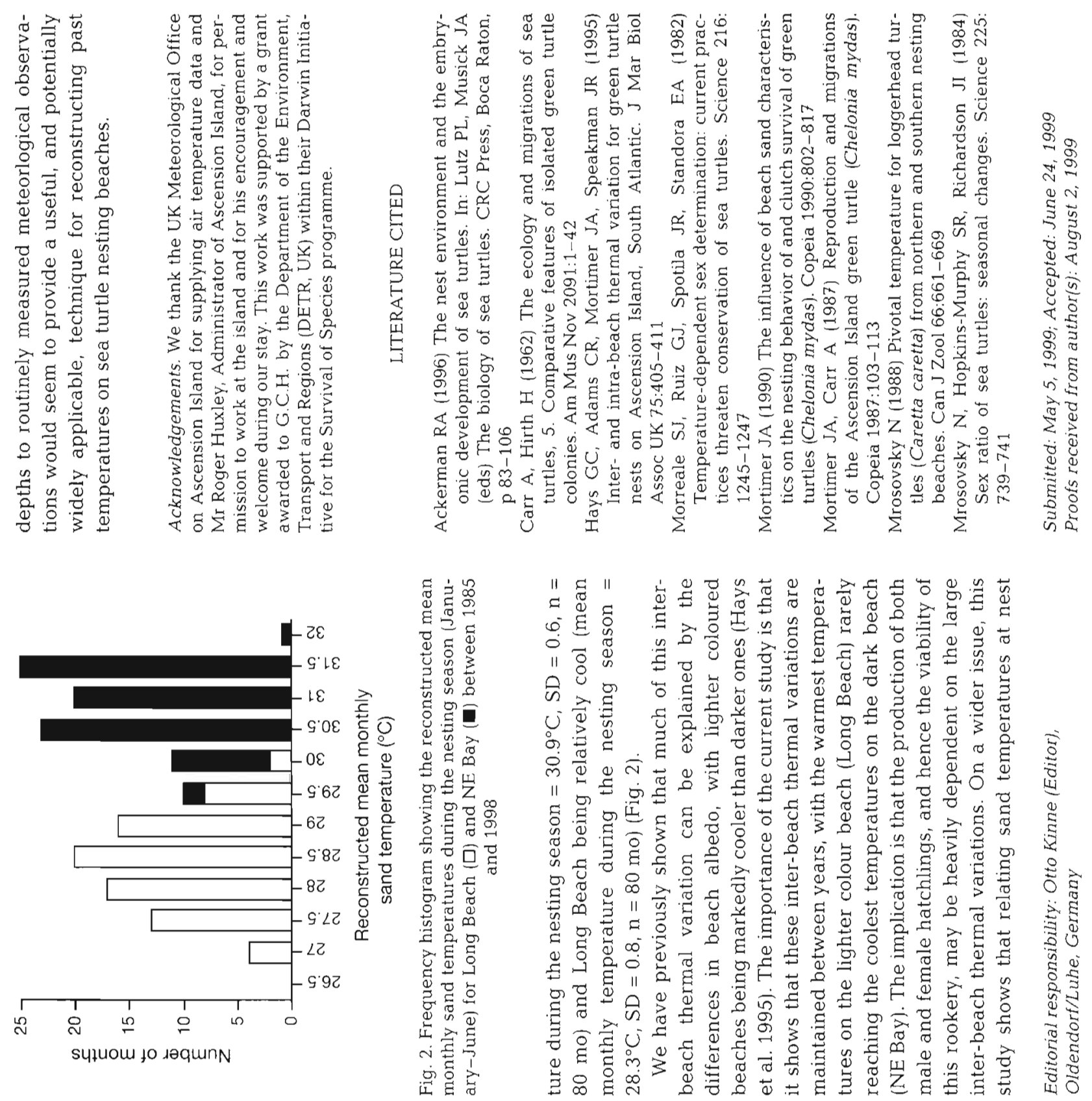